\title{
Disminución de infecciones bacterianas en el contexto de la pandemia por COVID-19 en un centro de referencia de enfermedades infecciosas
}

\section{Decrease in bacterial infections in the context of the COVID-19 pandemic at an infectious disease referral center}

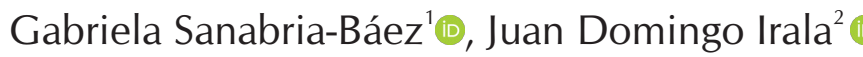 \\ ${ }^{1}$ Instituto de Medicina Tropical. Dirección de Investigación y Docencia. Asunción, Paraguay. \\ ${ }^{2}$ Instituto de Medicina Tropical. Laboratorio de Bacteriología. Asunción, Paraguay.
}

Señora Editora,

Hemos leído varios reportes de la disminución de enfermedades infecciosas durante la pandemia por COVID-19 ${ }^{(1-5)}$. Aunque se ha demostrado el beneficio colateral de controlar COVID-19 para otras enfermedades infecciosas respiratorias comunes, como la influenza e infecciones bacterianas, el impacto del control de infecciones y la política para prevenir el brote de COVID-19 sigue sin estar claro ${ }^{(6)}$. Esta breve revisión busca determinar si la incidencia de aislamientos bacterianos asociados a infecciones bacterianas estaría disminuyendo como reportan varios estudios.

Desde la adopción e implementación de las medidas de protección contra el SARS-CoV-2; el virus que causa la enfermedad por coronavirus 2019 (COVID19); y aún más con el registro de casos en Paraguay a inicios del 2020 y el aumento sostenidos de casos hasta la fecha, hemos visto una disminución ingresos hospitalarios a causa de enfermedades infecciosas bacterianas ${ }^{(5)}$.

En el contexto de las infecciones respiratorias agudas graves (IRAG), en el año 2018 la Vigilancia activa registró un total de 7.480 hospitalizaciones por infección respiratoria aguda reportadas en los 10 Centros Centinelas del país, durante año 2019, esta cifra ascendió a 8.984 hospitalizaciones, en lo que va del 2020 se han registrado alrededor de 150 casos de IRAG a nivel país, sin contar los casos de COVID-19 que desde este año se ha sumado como parte de la vigilancia de IRAG, el reporte del Ministerio de Salud Pública indica un total de 56.073 casos de COVID-19 en los primeros 10 meses del año ${ }^{(7)}$.

Esta situación país, también se refleja en las internaciones en el Instituto de Medicina Tropical, en donde en los últimos años el promedio anual de casos de meningitis bacteriana era de 19 y en lo que va del 2020 se han reportado solo 4 casos, con respecto a la neumonía bacteriana era de 319 y en el 2020 se registraron 15 casos, la mayoría en adultos; es así que revisamos todos los resultados microbiológicos de los pacientes ingresados en el Instituto de Medicina Tropical desde enero de 2016 a octubre de 2020, y observamos una disminución del $60 \%$ en el número de muestras procesadas (mediaanual8.717 entre 2016 - 2019 y 5.295 de enero a septiembre de 2020).

El aislamiento de Streptococcus pneumoniae causantes de neumonía y meningitis se encuentra actualmente en mínimos históricos para el laboratorio (Figura 1). Los datos de Neisseria meningitidis reportados en el

Correspondencia: Gabriela Sanabria Correo: gabysanabria@gmail.com

Recibido: 21/10/2020 Aceptado:15/01/2021

DOI: https://doi.org/10.31698/ped.48012021002

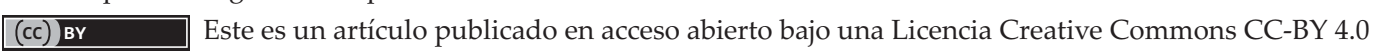


último quinquenio mostraron una actividad muy baja y en el caso de Haemophilus influenzae no se han registrado aislamiento en los últimos dos años (Figura 1).

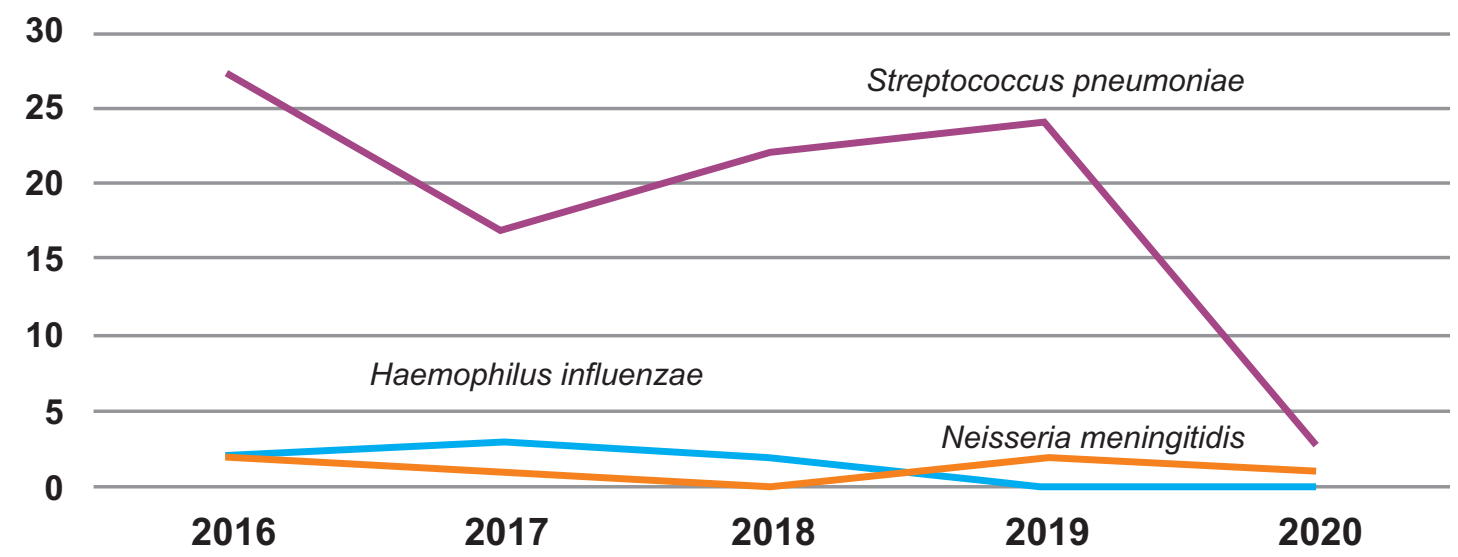

Figura 1. Aislamientos de bacteria causantes de Meningitis y Neumonía bacteriana 2016-2019.

Más notoria es la diminución en los aislamientos de Staphylococcus aureus, que en el último año se redujo un $57 \%$ con respecto al 2019, estos aislamientos fueron separados según provenían de infección de piel y partes blandas (IPPB) o de infecciones invasivas (IV) como neumonías, meningitis y sepsis (Figura 2).

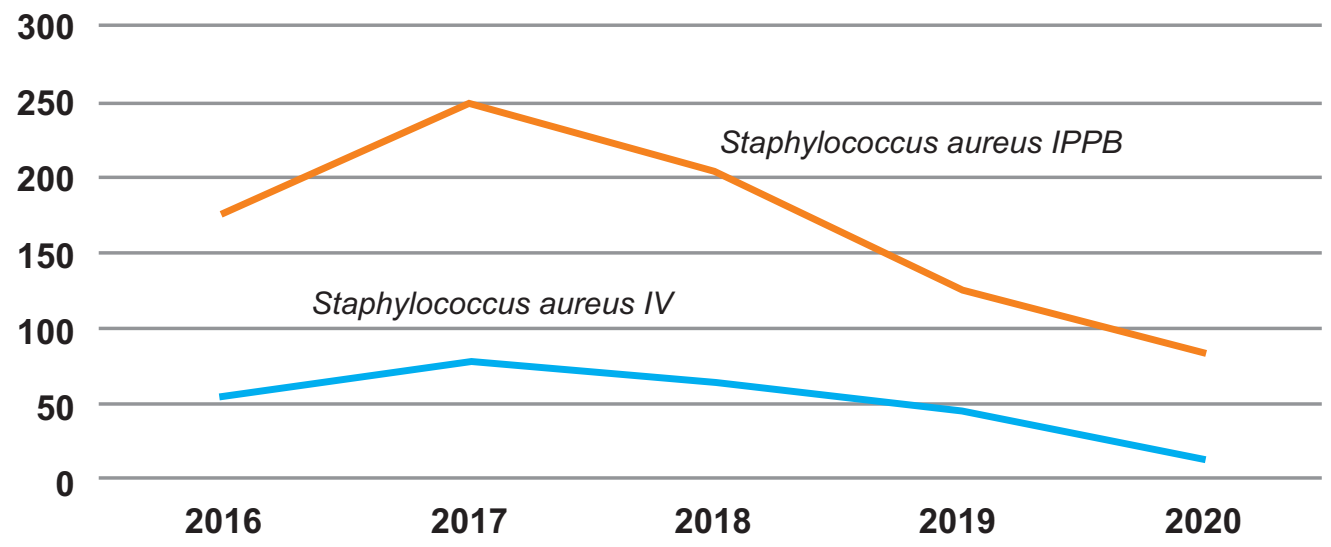

Figura 2. Frecuencia e aislamientos de Staphylococcusaureus 2016-2020.

La principal fortaleza de nuestro informe es que somos un centro de referencia de enfermedades infecciosas. La principal limitación es la variabilidad del muestreo microbiológico lo que podría no ser generalizables a otros entornos geográficos.

Estos resultados nos llevan a pensar que es probable que el uso de medidas comunitarias de mitigación para la pandemia de COVID-19 (por ejemplo, lavado de manos, uso de mascarillas, distanciamiento social, cierre de escuelas y teletrabajo) han contribuido enormemente en la disminución de aislamientos bacterianos. Sin embargo, dada la novedad de la pandemia COVID-19 y la incertidumbre de las continuas medidas de mitigación de la comunidad, es importante resaltar esta baja tasa de aislamientos para destacar esas medidas de mitigación como método de prevención a futuro de infecciones. 


\section{REFERENCIAS}

1. Mesquita, M. Impacto de la pandemia por SARS CoV 2 en la población pediátrica. Pediatr. (Asunción). 2020; 47(2):51-53. doi: https://doi.org/10.31698/ped.47022020001

2. Juan HC, Chao CM, Lai CC, Tang HJ. Decline in invasive pneumococcal disease during COVID-19 pandemic in Taiwan. J Infect. 2021;82(2):282-327. doi: https://doi.org/10.1016/j.jinf.2020.09.018

3. Weiss DJ, Bertozzi-Villa A, Rumisha SF, Amratia P, Arambepola R, Battle KE, et al. Indirect effects of the COVID-19 pandemic on malaria intervention coverage, morbidity, and mortality in Africa: a geospatial modelling analysis. Lancet Infect Dis. 2021;21(1):59-69. doi: https://doi.org/10.1016/S1473-3099(20)30700-3

4. Olsen SJ, Azziz-Baumgartner E, Budd AP, Brammer L, Sullivan S, Pineda RF, et al. Decreased influenza activity during the COVID-19 pandemic-United States, Australia, Chile, and South Africa, 2020. Am J Transplant. 2020;20(12):3681-3685. doi: https://doi.org/10.1111/ajt.16381
5. Adler H, Ball R, Fisher M, Mortimer K, Vardhan MS. Low rate of bacterial co-infection in patients with COVID19. Lancet Microbe. 2020;1(2):e62. doi: https://doi.org/ $10.1016 / S 2666-5247(20) 30036-7$

6. Ministerio de Salud Pública y Bienestar Social (MSPyBS). Plan De Respuesta Nacional al Eventual Ingreso del Coronavirus (COVID-19) V1. Asunción: MSPyBS; 2020.

7. Ministerio de Salud Pública y Bienestar Social (MSPyBS). Reporte COVID-19 [Internet]. Paraguay: DGVS; 2020. [citado oct. 10 2020] Disponible en: http://www.vigisalud.gov.py/page/\#vista_boletines_covi d19.html 